\title{
INTEGRASI BUDAYA PRESTASI PADA FUNGSI PERENCANAAN PEMBINAAN MUTU DOSEN
}

\author{
Wahyudin Noor ${ }^{1}$, Juhji ${ }^{2}$ \\ ${ }^{1}$ IAIN Syaikh Abdurrahman Siddik, Bangka, Bangka Belitung, Indonesia \\ 2UIN Sultan Maulana Hasanuddin, Serang, Banten, Indonesia \\ Email:wahyu_oche@yahoo.com ${ }^{1}$,juhji@uinbanten.ac.id²
}

\author{
DOI: http://doi.org/10.33650/al-tanzim.v4i1.919 \\ \begin{tabular}{l|l|l} 
Received: Januari 2020 & Accepted: Maret 2020 & Published: Maret 2020
\end{tabular}
}

\begin{abstract}
:
This paper aims to explain the implementation of the planning function of lecturer quality development at UIN Imam Bonjol Padang, West Sumatera and integrating the cultural values of achievement in the planning function. This research uses a qualitative approach. Data collection techniques are done through interviews, observation and documentation. Data analysis procedures use data reduction, data display, and verification. While the research subjects are leaders, lecturers, and students. The results of this study indicate that: a) The planning of lecturer quality development activities at UIN Imam Bonjol Padang, has been quite good. Nevertheless, the relatively minimal budgeting problems can affect the optimization of the realization of planned activities; $b$ ) Integrating the achievement cultural in the planning function of lecturer quality development activities in tertiary institutions, is to be an endeavor to initiate changes in tertiary institutions that constantly necessitates improved management in an increasingly efficient, effective and productive direction.
\end{abstract}

Key words : Achievement culture, development planning and lecturer quality

\begin{abstract}
Abstrak :
Tulisan ini bertujuan untuk menjelaskan tentang pelaksanaan fungsi perencanaan pembinaan mutu dosen di UIN Imam Bonjol Padang, Sumatera Barat, serta mengintegrasikan nilai-nilai budaya prestasi pada fungsi perencanaan tersebut. Penelitian ini menggunakan pendekatan kualitatif. Teknik pengumpulan data dilakukan melalui wawancara, observasi dan dokumentasi. Teknik analisis data menggunakan reduksi data, display data dan verifikasi. Sedangkan subyek penelitian adalah pimpinan, dosen dan mahasiswa. Hasil penelitian ini menunjukkan bahwa: a) Perencanaan kegiatan pembinaan mutu dosen di UIN Imam Bonjol Padang, telah cukup baik. Meskipun demikian, permasalahan penganggaran yang relatif masih minim dapat mempengaruhi optimalisasi realisasi rencana kegiatan yang telah diagendakan; $b$ ) Mengintegrasikan budaya prestasi pada fungsi perencanaan kegiatan pembinaan mutu dosen di perguruan tinggi, adalah menjadi sebuah ikhtiar untuk mengawali perubahan di perguruan tinggi yang senantiasa meniscayakan perbaikan manajemen ke arah yang semakin efisien, efektif dan produktif.
\end{abstract}

Kata Kunci : Budaya prestasi, perencanaan pembinaan dan mutu dosen 


\section{PENDAHULUAN}

Peradaban di era global saat ini mengamanatkan perguruan tinggi sebagai institusi pendidikan yang tertinggi untuk selalu berbenah diri dalam merespon kebutuhan lingkungan. Oleh karena itu, diperlukan usaha untuk dilakukannya perubahan organisasi secara berkesinambungan dengan melakukan perubahan pada beberapa elemen, misalnya, personel dan manajemen, yang merupakan bagian-bagian yang terlibat dalam proses kerja organisasi (Anatan \& Ellitan, 2007). Keterlibatan individu dan pihak manajemen, sangat menentukan kesuksesan proses perubahan organisasi.

Melihat pentingnya proses perubahan organisasi ini terhadap perkembangan global, maka yang harus dilakukan adalah, bagaimana membangun kesadaran seluruh unsur organisasi agar mau terlibat dalam proses perubahan tersebut. Kendatipun, perbedaan organisasi yang menjadi warna bagi anggota suatu organisasi (Husni, 2018), akan cukup memengaruhi cara organisasi melakukan perubahan. Namun demikian, pada situasi dan kondisi inilah, budaya organisasi (Baharun, 2016) yang fleksibel dan menyatu dengan praktik manajemen serta individu, akan berperan penting dalam proses percepatan perubahan dan pencapaian tujuan organisasi.

Secara teori, membangun budaya organisasi (Trang, 2013) memang dimungkinkan apabila terdapat sumber-sumber yang menjadi pendorong. Robert P. Vecchio (1999) misalnya, mengidentifikasi 4 (empat) faktor yang mendorong sumber budaya organisasi, yakni; keyakinan dan nilai-nilai pendiri organisasi, norma sosial organisasi, adaptasi eksternal dan integrasi internal. Sementara itu, dengan mengetahui sumber-sumber pendorong untuk melakukan perubahan tersebut, tentu sangat penting untuk mendiagnosis masalah-masalah yang dihadapi dan mungkin akan muncul saat proses perubahan berlangsung.

Diagnosis masalah dilakukan dengan mencari akar masalah yang ada, yaitu kondisi atau masalah apa yang bertentangan dengan situasi yang ada, komponen/bagian apa yang memerlukan perubahan, dan apa tujuan perubahan dilakukan (Anatan \& Ellitan, 2007). Oleh karena itu, budaya organisasi harus selalu diubah dan diperbaiki secara berkelanjutan (Pourrajab \& Ghani, 2017); (Sheikhalizadeh \& Piralaiy, 2017), terlebih lagi dalam menghadapi kecenderungan global dengan seperangkat nilainya yang semakin gencar. Ini penting, karena budaya organisasi mempengaruhi masa depan organisasi (Rashid, et al., 2004); (Alavi, et al., 2005); (Brahmasari \& Suprayetno, 2008); (Warsito, 2008); (MacIntosh \& Doherty, 2010); (Xaverius, 2016); (Mustafid, 2017) untuk berkembang ke tingkat yang lebih tinggi.

Denison (1990) dan Mishra (1995) mengungkapkan, budaya organisasi sejatinya adalah nilai-nilai, keyakinan dan prinsip-prinsip dasar yang merupakan landasan bagi sistem dan praktik-praktik manajemen serta perilaku yang meningkatkan dan menguatkan prinsip-prinsip tersebut (Saefullah, 2014). Artinya, bahwa dasar keberhasilan organisasi menjadi kuat terletak pada upaya mengelaborasikan budaya organisasi yang berisi nilai atau keyakinan ke dalam praktik-praktik manajemen dan perilaku layanannya. 
Para peneliti strategi misalnya, menyadari bahwa budaya organisasi merupakan sumber daya strategis (Wei, et al., 2014); (Nankervis, et al., 2016) yang secara potensial menghasilkan keunggulan kompetitif secara terus menerus (Barney, 1986); (Schoemaker, 1990); (Magalhaes, 2004). Di lain pihak, kebutuhan terhadap perencanaan, -sebagai satu dari beberapa aspek praktik manajemen- tentunya diharapkan dapat mengawal bagaimana organisasi seharusnya berpindah dari posisi sekarang ke posisi yang akan datang yang lebih baik. Karena, di dalam literatur manajemen sumber daya manusia strategis (Muhtarom, 2015); (Noor, 2017), misalnya, para ilmuwan semakin menyadari kebutuhan untuk terus membangun fleksibilitas di dalam organisasi (Milliman, et al., 1991); (MacDuffie, 1995); (Maulana, 2018). Artinya, mengelaborasikan praktik perencanaan sebagai salah satu fungsi manajemen, dengan budaya organisasi yang positif (Taurisa \& Intan, 2012), menuntut peran serta para anggota organisasi untuk secara proaktif memiliki kelenturan dalam menciptakan atau melahirkan dan menumbuh-kembangkan beragam bentuk prestasi organisasi dari rencana-rencana yang yang telah disusun (M. A. Wibowo \& Putra, 2016).

Pada konteks inilah, perguruan tinggi tentunya meniscayakan kehadiran budaya organisasi yang mampu 'membaluti' seluruh praktik perencanaan, termasuk perencanaan di bidang pembinaan mutu dosen. Di lain sisi, mendesain dosen menjadi bermutu, adalah bagian dari aktivitas pembinaan yang harus dilakukan oleh perguruan tinggi. Mendesain dosen seperti di atas, haruslah berangkat dari proses perencanaan pembinaan yang matang demi terbentuknya budaya prestasi di perguruan tinggi.

Mengintegrasikan budaya prestasi terhadap seluruh tahapan aktivitas perencanaan di bidang pembinaan mutu dosen sangatlah penting. Budaya prestasi menurut Tan (2002), dimaknai sebagai salah satu tipe budaya yang sangat mendorong bagaimana menghargai kinerja seseorang. Budaya prestasi juga adalah budaya organisasi yang menekankan pada pekerjaan yang dilakukan dari pada sekedar peran (Wibowo, 2016). Berangkat dari hal tersebut, peneliti tertarik untuk mengungkap fenomena tentang bagaimana tahapan perencanaan di bidang pembinaan mutu dosen dilakukan di UIN Imam Bonjol Padang ?, serta bagaimana kemudian tahapan-tahapan dari perencanaan pembinaan mutu dosen itu dapat diintegrasikan dengan nilai-nilai budaya prestasi ?.

\section{METODE PENELITIAN}

Metode penelitian ini menggunakan pendekatan kualitatif. Subjek penelitian yang ditentukan adalah pimpinan dan dosen UIN Imam Bonjol Padang sebagai jawaban atas pertanyaan penelitian. Pemilihan informan menggunakan purposive sampling dengan teknik snow ball sampling. Data yang diambil adalah data primer (informan), hasil observasi dan wawancara dengan beberapa pimpinan, dosen, pegawai dan mahasiswa UIN Imam Bonjol Padang. Selanjutnya, data sekunder yang terdiri atas buku arsip yang, khususnya yang berkenaan dengan produk penelitian dan pendukung, misalnya, Pedoman Akademik, Buku Rencana Induk Pengembangan IAIN Imam Bonjol Padang 
2013-2032, dokumentasi bagian perencanaan, dan lain sebagainya. Teknik Pengumpulan data dilakukan dengan; a) Observasi, b) Wawancara, dan c), Dokumentasi. Data yang diperoleh melalui hasil penelitian diolah sehingga memperoleh pemahaman yang jelas tentang permasalahan yang berkaitan dengan tujuan penelitian.

\section{HASIL DAN PEMBAHASAN}

Berdasarkan informasi dan data yang diperoleh di lapangan, ditemukan bahwa, perencanaan di UIN Imam Bonjol Padang terdiri dari Rencana Strategis I (2013-2017) dan Rencana Strategis II (2018-2022). Rencana Strategis I dan dan Rencana Strategis II merupakan program penguatan internal untuk menuju univeristas riset bereputasi internasional. Sedangkan Rencana Strategis III (2023-2027) dan Rencana Strategis IV (2028-2032) merupakan program penguatan internal untuk bersaing memperoleh tempat sebagai universitas riset bereputasi internasional dalam pengembangan Islam, ilmu dan teknologi berbasis keumatan dan kebangsaan (IAIN Imam Bonjol Padang, 2013).

Untuk mewujudkan seluruh tahapan fungsi perencanaan di bidang pembinaan mutu dosen di UIN Imam Bonjol Padang, sebagaimana dijelaskan Wakil Rektor I UIN Imam Bonjol Padang, Ikhwan (Ikhwan, 2017), diawali dengan melakukan kegiatan analisis SWOT (Strengths, Weaknesses, Opportunities, Threats), yakni kegiatan menganalisis sumber kekuatan, kelemahan, peluang dan tantangan UIN Imam Bonjol Padang. Hasil analisis menghasilkan RIP (Rencana Induk Pengembangan) UIN Imam Bonjol Padang 2013-2032 yang berisi arah kebijakan, tujuan, sasaran dan, termasuk usahausaha di bidang pembinaan mutu dosen yang memungkinkan dapat dilakukan.

Selain RIP (Rencana Induk Pengembangan), sebagaimana diungkapkan Wakil Rektor I UIN Imam Bonjol Padang, Ikhwan (Ikhwan, 2017), beberapa dokumen lain yang lebih operasional, misalnya, Renstra (Rencana Strategis) dan RKT (Rencana Kerja Tahunan) juga digunakan untuk menggambarkan postur yang ingin dicapai oleh UIN Imam Bonjol Padang ke depan (IAIN Imam Bonjol Padang, 2013).

Pada konteks tujuan, sejak awal pelaksanaan kegiatan pengembangan atau pembinaan mutu dosen di UIN Imam Bonjol Padang, sebagaimana dikatakan Rektor UIN Imam Bonjol Padang, Eka Putra Wirman (2017), yakni meningkatkan profesionalisme dosen. Artinya, dosen UIN Imam Bonjol Padang sejatinya memang harus menguasai dan expert di bidang ilmunya, terampil menulis dan berkarya, disiplin dan tertib administrasi, berkepribadian yang baik dan mampu menularkan sekaligus menggerakkan mahasiswa dengan semangat ilmunya.

Pada aspek kebijakan, arah kebijakan UIN Imam Bonjol Padang terkait dengan pembinaan mutu dosen, sebagaimana dijelaskan Rektor UIN Imam Bonjol Padang, Eka Putra Wirman (2017), yakni memperkuat komitmen dan profesionalisme dosen yang sesuai dengan kompetensi dan kualifikasinya dalam mewujudkan pelayanan prima. Kebijakan Rektor diikuti oleh kebijakan yang lebih operasional pimpinan Fakultas. Yufni Faisol (2017), misalnya, Dekan Fakultas Adab dan Humaniora UIN Imam Bonjol Padang menyebutkan, 
pertama, mendorong dan memotivasi dosen-dosen melanjutkan studi dan kariernya; kedua, memotivasi dosen untuk lebih banyak memiliki karya tulis, mulai dari jurnal, menulis di jurnal, kemudian mendorong dosen untuk melakukan penelitian, memfasilitasi dosen mengikuti event-event ilmiah, baik tingkat regional maupun nasional, seperti mengirim dosen mengikuti seminarseminar, dan lain-lain sebagainya; ketiga, mengalokasikan dana untuk menunjang kegiatan-kegiatan dimaksud.

Pada konteks program pembinaan mutu dosen, bertolak dari kebijakan memperkuat komitmen dan profesionalisme dosen sesuai dengan kompetensi dan kualifikasi dalam mewujudkan pelayanan prima. Untuk merealisasikan arah kebijakan di bidang pembinaan mutu dosen ini, secara umum disusunlah program di bidang pembinaan mutu dosen, meliputi; 1) pengembangan dosen; 2) peningkatan standar mutu kegiatan pengelolaan dosen; 3) pengembangan dan penerapan sistem pengembangan karir dosen sesuai dengan kebutuhan; dan, 4) peningkatan efektivitas dan tindak lanjut hasil evaluasi kinerja dosen (Asri, 2018).

Adapun, pembagian berbagai program pembinaan mutu dosen, di UIN Imam Bonjol Padang, relatif bervariasi. Artinya, tiap-tiap unit di lingkungan UIN Imam Bonjol Padang, memiliki jadwal yang berbeda antar tiap unit penyelenggara. Seminar, diskusi, pelatihan, workshop dan seterusnya, satu sama lain antar unit berbeda, tergantung dari unit yang menyelenggarakannya (Wirman, 2017). Di samping itu, beberapa di antaranya tidak terjadwal, misalnya, kegiatan konseling (Bukhari, 2017).

Di UIN Imam Bonjol Padang, pembinaan mutu dosen secara teknis, menurut Ketua LPM UIN Imam Bonjol Padang, Hetti Waluati Triana (2017), prosedurnya biasanya diawali dengan melakukan survei-survei ataupun evaluasi yang terkait langsung pada upaya peningkatan mutu dan produktivitas dosen (Ikhwan, 2017). Pada konteks penganggaran, secara umum UIN Imam Bonjol Padang di setiap tahunnya memiliki dana sekitar \pm 140 miliar, termasuk di dalamnya sekitar $30 \mathrm{M}$ atau seperlima dari anggaran yang ada, adalah dana untuk beberapa kegiatan yang bersifat pembinaan atau pengembangan mutu dosen. Kendatipun demikian, Wakil Rektor I UIN Imam Bonjol Padang, Ikhwan (2017), mengakui bahwa dana-dana untuk kegiatan pembinaan mutu dosen tersebut, relatif masih kurang.

Dari beberapa temuan penelitian tersebut di atas, dapat diketahui bahwa; perencanaan kegiatan pembinaan mutu dosen di UIN Imam Bonjol Padang secara umum telah dilakukan dengan cukup baik, karena seluruh tahapan dari aktivitas perencanaan kegiatan pembinaan mutu dosen telah dilakukan. Misalnya, adanya kegiatan menganalisis untuk menghasilkan arah kebijakan, tujuan, sasaran yang memungkinkan bisa dilakukan dalam bidang pembinaan mutu dosen melalui analisis SWOT (strengths, weaknesses, opportunities, threats). Kegiatan analisis ini, berarti kegiatan forecasting, yakni meramalkan usaha, kegiatannya diawali dengan melakukan (Husni, 2018). Pembinaan mutu dosen, selalu merujuk pada tujuan, yakni profesionalisme dosen yang selaras dengan tuntutan zaman. 
Kendatipun demikian, persolan penganggaran misalnya, ditemukan bahwa, minimnya anggaran kegiatan pembinaan mutu dosen yang direncanakan, yakni \pm 30 Milyar dari 140 Milyar (sekitar 20\% untuk kegiatan pembinaan) dari dana yang diterima setiap tahun. Sedikitnya anggaran berdampak pada kurang maksimalnya kegiatan dan pelibatan dosen dalam program-program pembinaan mutu dosen.

Atas dasar itu, budaya prestasi pada perencanaan pembinaan mutu dosen diyakini dapat menjadi upaya mengawali perubahan perbaikan kinerja organisasi perguruan tinggi. Untuk itu, perlu kiranya menaruh perhatian terhadap pentingnya mengelola kegiatan-kegiatan di bidang pembinaan mutu dosen melalui intervensi pada perencanaan yang mengintegrasikan atas nilainilai yang mengglobal. Pada konteks situasi dan kondisi itulah, budaya organisasi yang fleksibel tentunya dapat berperan untuk mempercepat proses perubahan (Saefullah, 2014).

Budaya prestasi pada aktivitas perencanaan di bidang pembinaan mutu dosen, adalah suatu konsep kegiatan atau ikhtiar proses yang sangat penting demi peningkatan mutu dosen, baik secara pribadi atau kolektif menuju dosen berorientasi global. Budaya prestasi pada perencanaan pembinaan mutu dosen sejatinya merupakan suatu proses pemikiran, baik secara garis besar maupun secara mendetail dari suatu kegiatan atau pekerjaan di bidang pembinaan mutu dosen yang dapat dilakukan dengan 7 (tujuh) tahapan, yaitu; 1) Forecasting, 2) Objective, 3) Policies, 4) Programmes, 5) Schedules, 6) Procedures, and 7) Budget.

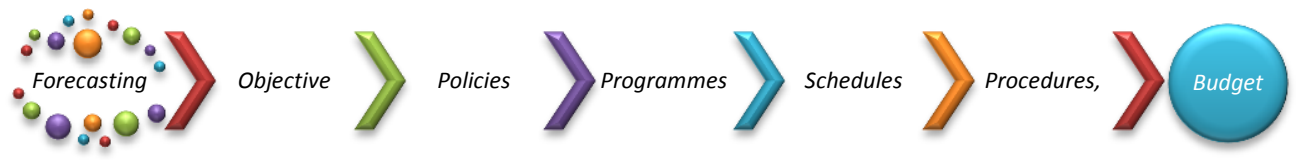

Gambar 1 : Pembinaan mutu dosen di UIN Imam Bonjol Padang

Forecasting adalah meramalkan, memproyeksikan atau mengadakan taksiran terhadap berbagai kemungkinan yang akan terjadi sebelum rencana yang lebih pasti dapat dilakukan (Sujoko, 2017; Susilawati, 2017; Hanan, 2018). Forecasting pembinaan mutu dosen dapat dilakukan dengan metode analisis SWOT (Muhamad, 2014), yakni metode yang digunakan untuk mengevaluasi kekuatan (strengths), kelemahan (weaknesses), peluang (opportunities) dan ancaman (threats) terkait dengan kegiatan/program pembinaan mutu dosen yang direncanakan dilaksanakan untuk kemudian didokumentasikan menjadi pedoman kerja. Beberapa forecasting (perkiraan) kegiatan pembinaan mutu dosen meliputi forecasting di bidang: (1) pendidikan dan pengajaran, (2) penelitian, dan (3) pengabdian kepada masyarakat.

Objective atau tujuan adalah nilai yang akan dicapai atau diinginkan oleh seseorang atau organisasi (Muhamad, 2014). Tujuan pembinaan mutu dosen, dapat meliputi: pertama, meningkatkan profesionalisme dan mutu dosen; kedua, mendorong dosen agar menjadi benchmarking dan memiliki networking dengan berbagai pihak dan elemen organisasi serta perguruan tinggi ternama, baik pada level nasional maupun internasional.

Policies merupakan prinsip yang menjadi aturan dalam kegiatan yang terus menerus, setidak-tidaknya selama jangka waktu pelaksanaan rencana 
suatu organisasi (Muhamad, 2014). Policies pembinaan mutu dosen, meliputi kebijakan dasar (basic policies) yang ditentukan oleh top management atau pimpinan puncak perguruan tinggi, yakni kebijakan memperkuat komitmen atas peningkatan profesionalisme dan mutu dosen serta mengawal dosen untuk menjadi benchmarking dan memiliki networking.

Programmes adalah sederatan kegiatan yang digambarkan untuk melaksanakan policies (Mejia, 2001). Program itu harus merupakan suatu kegiatan yang terikat erat dan tidak dapat dipisahkan dengan tujuan yang telah ditentukan dalam organisasi. Beberapa ragam program manajemen pembinaan mutu dosen, sekurang-kurangnya meliputi atas; 1) Sosialisasi dan orientasi kerja dosen, 2) Pendidikan dosen, 3) Penilaian dan pengalaman kerja dosen, 4) Coaching, mentoring dan konseling dosen, 5) Pelatihan keterampilan, teknis dan diversitas dosen, 6) Pengembangan manajemen, dan 7) Manajemen talenta.

Kegiatan sosialisasi adalah proses yang harus dilalui, khususnya dosen baru untuk mempelajari pengetahuan, nilai, norma, sikap dan perilaku yang tepat agar dapat berpartisipasi secara efektif di perguruan tinggi. Sedangkan orientasi kerja dosen, yakni kegiatan mengenalkan kepada, khususnya dosen baru tentang organisasi perguruan tinggi, dengan tugas-tugas baru, struktur organisasi dan kepemimpinan dengan kelompok kerja. Selain itu, orientasi sebagaimana menurut Mejia (2001) merupakan proses memberi tahu kepada dosen baru tentang apa yang diharapkan dari mereka di pekerjaan dan membantu mengatasi stres di masa transisi (Uwes, 1999).

Pendidikan dosen dapat dilakukan melalui dua cara, yaitu; pembelajaran di tempat kerja, dan pendidikan formal. Pembelajaran di tempat kerja dengan bentuk kegiatannya dapat berupa workshop, penataran, lokakarya, seminar, diskusi, simposium dan sebagainya. Sedangkan pendidikan formal dosen berupa studi lanjut gelar S-2 dan S-3 (Kaswan \& Akhyadi, 2015), pendidikan post doctoral, pendidikan profesional atau spesialisasi, di dalam atau di luar negeri.

Asumsi utama penggunaan pengalaman kerja untuk pembinaan mutu dosen adalah; pembinaan cenderung terjadi ketika ada ketidaksesuaian antara keterampilan dosen dan pengalaman masa lalu, serta keterampilan yang diperlukan untuk pekerjaan atau tugas tersebut. Konkretnya, pengalaman merupakan media yang mampu merefleksikan bentuk-bentuk penugasan dosen, baik yang berkaitan tugas tri dharma maupun praktik-praktik pengembangan manajemen perguruan tinggi.

Coaching, mentoring dan konseling dosen. Kegiatan coaching, misalnya, merupakan kunci pembuka potensi seorang dosen untuk memaksimalkan kinerjanya di bidang tri dharma perguruan tinggi. Inti dari coaching adalah memberdayakan dosen dengan memfasilitasi pembelajaran diri dan perbaikan kinerja. Sedangkan mentoring merupakan upaya mendukung seorang dosen sehingga dapat berkembang lebih efektif (Kaswan \& Akhyadi, 2015). Hasil mentoring dapat diukur berdasarkan keterampilan, wawasan, sikap, maupun kompetensi yang diperoleh. Sementara konseling adalah diskusi/pembahasan masalah dengan personil dosen dengan tujuan umum membantu dosen mengatasi masalah (Roberson, 2013). 
Pelatihan keterampilan, teknis dan diversitas dosen. Kompetensi interpersonal merupakan salah satu keterampilan yang esensial dan perlu dimiliki oleh dosen. Kemampuan membuat orang lain merasa penting, kemampuan memahami orang lain dan kemampuan mendengarkan orang lain menjadi sangat esensial bagi dosen. Pelatihan diversitas bagi dosen setidaknya dimaksudkan untuk meningkatkan kesadaran keragaman pada diri dosen, mempromosikan sikap antar-kelompok dan memotivasi perilaku positif antar civitas perguruan tinggi (Kaswan \& Akhyadi, 2015).

Pengembangan manajemen merupakan salah satu cara utama bagi perguruan tinggi untuk meningkatkan dan mengembangkan kemungkinan para pimpinan, baik top management, midle management atau low management perguruan tinggi menjadi efektif (Hatum, 2010). Atas dasar itulah, pimpinan di setiap level perguruan tinggi, yakni Rektor, Dekan, Kepala Unit, Ketua Jurusan, Ketua Program Studi, yang pada akhirnya bertanggung jawab atas pembuatan keputusan untuk mengubah strategi dan struktur organisasi perguruan tinggi.

Manajemen talenta menurut Andres Hatum, merupakan aktivitas strategis yang diselaraskan dengan strategi bisnis/organisasi yang bertujuan menarik, mengembangkan dan mempertahankan pegawai yang bertalenta pada setiap level organisasi. Organisasi semisal perguruan tinggi dapat saja memfokuskan usaha manajemen talenta, terutama dosen "dengan potensi tinggi", yang sering disebut dengan high pos (Muhamad, 2014).

Schedules adalah pembagian program yang harus diselesaikan menurut urutan-urutan waktu tertentu. Dalam keadaan terpaksa schedules dapat berubah, tetapi program dan tujuan tidak berubah (Muhamad, 2014). Pada praktiknya, program-program pembinaan mutu dosen sejatinya memang meniscayakan penjadwalan. Kendati dalam praktiknya pun, meniscayakan terjadinya perbedaan antar unit dari sisi urutan waktu, tempat dan para pelakunya.

Prosedur adalah suatu gambaran sifat atau metode untuk melaksanakan suatu kegitan atau pekerjaan. Prosedur berbicara tentang bagaimana melaksanakannya (Muhamad, 2014). Prosedur pada fungsi perencanaan pembinaan mutu dosen, dapat dilakukan melalui analisis data yang bersumber dari dokumen resmi terkait rencana-rencana yang akan dilaksanakan. Dari data itulah, untuk merealisasikannya diperlukan adanya SOP (Standard Operating Procedure) untuk masing-masing kegiatan.

Budget adalah suatu taksiran atau perkiraan biaya yang harus dikeluarkan dan atau pendapatan yang diharapkan diperoleh di masa yang akan datang guna memperoleh hasil yang diharapkan (Novianti, 2017). Menentukan budget untuk realisasi program/kegiatan pembinaan mutu dosen dapat dilakukan melalui benchmarking dengan perguruan tinggi lain yang berkulitas. 


\section{KESIMPULAN}

Mengintegrasikan budaya prestasi dengan perencanaan pembinaan mutu dosen di perguruan tinggi, adalah sebuah langkah maju untuk mengawali perubahan. Di sisi lain, satu di antara tantangan yang akan dihadapi oleh perguruan tinggi di masa depan adalah menciptakan organisasi atau institusi yang semakin beragam, tetapi sekaligus menuntut manajemen yang semakin efisien, efektif dan produktif.

Kebutuhan untuk bisa mengembangkan dan atau membina kualitas dosen di era global saat ini dirasa sangat penting, dan tampak menjadi kebutuhan nyata perguruan tinggi mewujudkan pengakuan internasionalnya. Untuk mewujudkan itu, upaya yang dapat dilakukan adalah mengembangkan sistem dan praktik manajemen yang mempertimbangkan nilai-nilai yang berkembang di era global mutlak penting dilakukan.

Budaya prestasi pada perencanaan kegiatan pembinaan mutu dosen di perguruan tinggi, merupakan ikhtiar pemikiran yang bisa diterapkan untuk merespon berbagai tuntutan dan perkembangan lingkungan yang meniscayakan perubahan. Namun demikian, proses pengintegrasian budaya prestasi pada sebuah perencanaan kegiatan pembinaan mutu dosen, pastinya membutuhkan pengorbanan dan kesadaran dari seluruh elemen di perguruan tinggi untuk dapat terlibat dalam perubahan. Tanpa itu, perubahan tidak akan pernah terjadi.

\section{DAFTAR PUSTAKA}

Alavi, M., Kayworth, T. R., \& Leidner, D. E. (2005). An Empirical Examination of the Influence of Organizational Culture on Knowledge Management Practices. Journal of Management Information Systems, 22(3), 191-224.

Anatan, L., \& Ellitan, L. (2007). Manajemen Sumber Daya Manusia dalam Bisnis Modern. Bandung: Alfabeta.

Asri, Y. N. (2018). Hubungan Persepsi Mahasiswa pada Kinerja Dosen terhadap Tingkat Kelulusan Mahasiswa. Al-Tanzim: Jurnal Manajemen Pendidikan Islam, 2(2), 129-136.

Baharun, H. (2016). Manajemen Kinerja Dalam Meningkatkan Competitive Advantage Pada Lembaga Pendidikan Islam. At-Tajdid: Jurnal Ilmu Tarbiyah, 5(2), 243-262.

Barney, J. B. (1986). Strategic Factor Markets: Expectations, Luck, and Business Strategy. Management Science, 32(10), 1231-1241.

Brahmasari, I. A., \& Suprayetno, A. (2008). Pengaruh Motivasi Kerja, Kepemimpinan dan Budaya Organisasi terhadap kepuasan Kerja Karyawan serta Dampaknya pada Kinerja Perusahaan (Studi Kasus pada PT. PEI HAI International Wiratama Indonesia). Jurnal Manajemen dan Kewirausahaan, 10(2), 124-135.

Bukhari, B. (2017). Interview. Anduring, Kuranji, Padang.

Denison, D. R. (1990). Corporate Culture and Organizational Effectiveness. New York: John Wiley \& Sons. 
Denison, D. R., \& Mishra, A. K. (1995). Toward a Theory of Organizational Culture and Effectiveness. Organization Science, 6(2), 204-223.

Faisol, Y. (2017). Intreview. Anduring, Kuranji, Padang.

Hanan, A. (2018). Analisis Manajemen Strategik Kepala MTs Ishlahul Muslimin Senteluk Lombok Barat Perspektif SWOT. Manageria: Jurnal Manajemen Pendidikan Islam, 3(1), 157-171.

Hatum, A. (2010). Next Generation Talent Management: Talent Management to Survive Turmoil. London: Palgrave Macmillan.

Husni, M. (2018). Membangun Budaya Organisasi Berbasis Religius. Al-Tanzim: Jurnal Manajemen Pendidikan Islam, 2(1), 64-79.

IAIN Imam Bonjol Padang. (2013). Rencana Induk Pengembangan IAIN Imam Bonjol Padang 2013-2032. Padang: IAIN IB.

Ikhwan, M. (2017). Interview. Anduring, Kuranji, Padang.

Kaswan, K., \& Akhyadi, A. S. (2015). Pengembangan Sumber Daya Manusia; dari Konsepsi, Paradigma dan Fungsi sampai Aplikasi. Bandung: Alfabeta.

MacDuffie, J. P. (1995). Human Resource Bundles and Manufacturing Performance: Organizational Logic and Flexible Production Systems in the World Auto Industry. Ilr Review, 48(2), 197-221.

MacIntosh, E. W., \& Doherty, A. (2010). The Influence of Organizational Culture on Job Satisfaction and Intention to Leave. Sport Management Review, 13(2), 106-117.

Magalhaes, R. (2004). Organizational Knowledge and Technology: An ActionOriented Perspective on Organization and Information Systems. Amazon: Edward Elgar Pub.

Maulana, I. R. (2018). Pembangunan Fleksibel Dashboard untuk Monitoring Organisasi. Bandung: Universitas Pasundan.

Mejia, G. (2001). Managing Human Resources. London: Prentice Hall.

Milliman, J., Glinow, M. A. Von, \& Nathan, M. (1991). Organizational Life Cycles and strategic International Human Resource Management in Multinational Companies: Implications for Congruence Theory. Academy of Management Review, 16(2), 318-339.

Muhamad, M. (2014). Manajemen Bank Syariah. Jakarta: PT Raja Grafindo Persada.

Muhtarom, A. (2015). Implementasi Manajemen Sumber Daya Manusia dalam Peningkatan Profesionlitas Dosen Perguruan Tinggi Agama Islam Provinsi Banten. Tarbawi: Jurnal Keilmuan Manajemen Pendidikan, 1(2), 117-130.

Mustafid, H. (2017). Peningkatan Kinerja Aparatur Sipil Negara melalui Budaya Organisasi. Tarbawi: Jurnal Keilmuan Manajemen Pendidikan, 3(1), 1-14.

Nankervis, A., Rowley, C., \& Salleh, N. (2016). Asia Pacific Human Resource Management and Organisational Effectiveness: Impacts on Practice. Chandos Publishing.

Noor, W. (2017). Mengintegrasikan Manajemen Sumber Daya Manusia di Madrasah. Tarbawi: Jurnal Keilmuan Manajemen Pendidikan, 3(2), 153-167. 
Novianti, N. (2017). Teaching Character Education to College Students Using Bildungsromans. International Journal of Instruction, 10(4), 255-272.

Pourrajab, M., \& Ghani, M. F. A. (2017). The Relationship between School Organizational Culture and Characters of School Stakeholders: Students' Perceptions. MOJEM: Malaysian Online Journal of Educational Management, $3(2), 18-31$.

Rashid, Z. A., Sambasivan, M., \& Rahman, A. A. (2004). The Influence of Organizational Culture on Attitudes toward Organizational Change. Leadership E Organization Development Journal, 25(02), 161-179.

Roberson, Q. M. (2013). The Oxford Handbook of Diversity and Work. Oxford: Oxford University Press.

Saefullah, U. (2014). Manajemen Pendidikan Islam. Bandung: Pustaka Setia.

Schoemaker, P. J. H. (1990). Strategy, Complexity, and Economic Rent. Management Science, 36(10), 1178-1192.

Sheikhalizadeh, M., \& Piralaiy, E. (2017). The Effects of Organizational Culture on University's Academic Staff Knowledge Management. MOJEM: Malaysian Online Journal of Educational Management, 4(1), 17-31.

Sujoko, E. (2017). Strategi Peningkatan Mutu Sekolah Berdasarkan Analisis SWOT di Sekolah Menengah Pertama. Kelola: Jurnal Manajemen Pendidikan, 4(1), 83-96.

Susilawati, I. M. (2017). Analisis SWOT sebagai Dasar Strategi Branding pada Madrasah Ibtidaiyah Alhidayah, Cireunde, Ciputat. Tarbawi: Jurnal Keilmuan Manajemen Pendidikan, 3(1), 111-128.

Tan, V. S. (2002). Changing Your Corporate Culture. Singapore: Times Books International.

Taurisa, C. M., \& Intan, R. (2012). Analisis Pengaruh Budaya Organisasi dan Kepuasan Kerja terhadap Komitmen Organisasional dalam Meningkatkan Kinerja Karyawan (Studi pada PT. Sido Muncul Kaligawe Semarang). Jurnal Bisnis Dan Ekonomi, 19(2), 170 - 187.

Trang, D. S. (2013). Gaya Kepemimpinan dan Budaya Organisasi serta Pengaruhnya terhadap Kinerja Karyawan. Jurnal EMBA, 1(3), 208-216.

Triana, H. W. (2017). Interview. Anduring, Kuranji, Padang.

Uwes, S. (1999). Manajemen Pengembangan Mutu Dosen. Jakarta: Logos Wacana.

Vecchio, R. P. (1999). Organzational Behavior: Core Concepts. Canada: SouthWestern College Pub.

Warsito, B. (2008). Pengaruh Budaya Organisasi dan Lingkungan Kerja terhadap Organizational Citizenship Behavior, Motivasi dan Kinerja (Survey pada Karyawan Hotel Berbintang di Kota Malang dan Batu). Jurnal Ekonomi Modernisasi, 4(2), 83-96.

Wei, Y. S., Samiee, S., \& Lee, R. P. (2014). The Influence of Organic Organizational Cultures, Market Responsiveness, and Product Strategy on Firm Performance in an Emerging Market. Journal of the Academy of Marketing Science, 42(1), 49-70. 
Wibowo, M. A., \& Putra, Y. S. (2016). Pengaruh Motivasi dan Budaya Organisasi terhadap Kepuasan Kerja serta Implikasinya Terhadap Kinerja Karyawan Pada Rumah Sakit Umum (RSU) Salatiga. Among Makarti, 9(17), 1-20.

Wibowo, W. (2016). Budaya Organisasi; Sebuah Kebutuhan untuk Meningkatkan Kinerja Jangka Panjang. Jakarta: PT Raja Grafindo Persada.

Wirman, E. P. (2017). Kebijakan Rektor: Peningkatan Kinerja Dosen, Slide, disampaikan pada acara Sosialisasi Pedoman BKD (Beban Kerja Dosen) IAIN Imam Bonjol Padang di Hotel Rocky Plaza Hotel Padang pada tanggal 21-21 Januari 2017. Padang: IAIN Imam Bonjol.

Xaverius, S. S. (2016). Pengaruh Budaya Organisasi terhadap Kepuasan Kerja, Komitmen Organisasional dan Intention to Leave (Studi pada Karyawan PT. Bitung Mina Utama). Jurnal Bisnis dan Manajemen, 3(1), 94-108. 